\title{
MODULAR RECONFIGURABLE MACHINE TOOLS: DESIGN, CONTROL AND EVALUATION
}

\author{
J. Padayachee ${ }^{1}$, G Bright ${ }^{2}$ and I. Masekamela ${ }^{3}$ \\ ${ }^{1,2}$ School of Mechanical Engineering \\ University of KwaZulu Natal, South Africa \\ 1203505399@ukzn.ac.za, 2brightg@ukzn.ac.za \\ ${ }^{3}$ Council for Scientific and Industrial Research (CSIR) \\ South Africa
}

\begin{abstract}
The reconfigurable manufacturing system (RMS) paradigm encapsulates methodologies that enable manufacturing systems to cope effectively with market and product changes. This research presents the design and evaluation of modular reconfigurable machine (MRM) tools as a novel machining solution within the scope of RMS. Mechanical and control designs are presented, outlining the development of this novel machining system. The property of hardware modularity displayed by MRMs enables an adjustment of system functionality and the synergistic redistribution of system resources between production streams, thus facilitating inter-process capacity scaling. Scalable production capacity and adjustable system functionality are the key objectives of reconfigurable manufacturing.
\end{abstract}

Index terms: Reconfigurable Manufacturing Systems, Modular Reconfigurable Machines, Open Architecture Control, Modular Machine Control

\section{OPSOMMING}

Die paradigma van 'n herkonfigureerbare vervaardigingstelsel (HVS) bevat metodologieë waarmee vervaardigingstelsels kan tred hou met mark- en produkveranderings. Die navorsing hou die ontwerp en evaluering van modulêre masjiengereedskap voor as 'n nuwerwetse oplossing vir die herkonfigurasievraagstuk. Meganiese- en beheerontwerpe word voorgestel vir die ontwikkeling/ontplooiing van nuwe masjineringstelsels.

Die modulêre eienskappe van 'n HVS werk stelselplooibaarheid in die hand via 'n sinergistiese herdistribusie van stelselbronne aan produksievloeie om sodoende verlangde proseskapasiteit tegemoet te kom. 


\section{INTRODUCTION}

The rapid introduction of new products, regular updates in technology, and the need for customised products requires regular changes in the content and diversity of an enterprise product portfolio. The short production life of goods, and constantly changing consumer requirements, introduce further instability into the demand for specific items. The paradigm of RMS had begun to emerge in the late 1990s, necessitated by the nonresponsiveness of dedicated manufacturing systems (DMS) and flexible manufacturing systems (FMS) with regard to market and product changes. The failure to provide an effective response within DMS is attributed to the dedicated nature of the automation employed in the system. Dedicated machine tools (DMTs) are characteristic of DMS, capable of producing a high volume of units rapidly and cost effectively while maintaining high standards of quality [1].

The disadvantage of DMTs is their inability to provide adjustable functionality and scalability of system capacity. The implementation of DMTs in a system is only feasible economically when the demand for a specific product is high. The flexible manufacturing system (FMS) paradigm was introduced in the 1970s to address the problem of inflexibility inherent in DMS [2]. Computer numerically controlled machines (CNC machines) are characteristic of FMS $[6,7]$. These machines are designed to provide generic processing capabilities, thereby making FMS highly flexible. Conversely, CNCs do not provide an effective solution to capacity scaling and often possess excessive functionality, resulting in FMS being an expensive system with significantly longer payback periods than DMS [3, 8].

The formulation of the RMS paradigm required the reengineering of production machines that impart defining characteristics to the system. Mehrabi et al. [9] identify the fixed mechanical architectures and proprietary control systems found in CNC and DMT equipment as the specific drawback in effectively implementing these classes of equipment in RMS. Koren et al.[3] proposed the development of reconfigurable machine tools (RMTs) as a new category of equipment for use in RMS. Reconfigurable machines are to possess modifiable mechanical architectures and open control systems that overcome the problem of software control execution. The sphere of reconfigurable machinery has been developing over the past decade, sparking global debates on the characteristics and architectures that these machines should exhibit. The development of reconfigurable equipment has yet to reach a point of convergence, spurring further international research efforts in the quest for a unified design solution.

This paper presents the formulation of modular reconfigurable machine (MRM) tools for RMS, a new class of production machines, which by virtue of their modular characteristics offer the reconfigurability required by RMS to provide a rapid response to market or product changes. Section 2 of this paper presents foundational methodologies for MRM design and a review of related international research efforts. Sections 3 and 4 present MRM design from mechanical and electronic control perspectives. Section 5 addresses matters of machine reconfiguration and the scalability of production capacity through the redistribution of machines and modularised units of hardware between different product streams in a system. Section 6 presents a methodology and an example for assessing the integrity of modularised machine structures. The paper concludes with discussions on MRM performance and a description of future work.

\section{RELATED WORK}

\subsection{Structural design methodologies}

MRMs are mechanically modular machine tools. Methodologies supporting the design of such machine tools have been adapted from the international research of machine tool experts. Shinno and Ito developed a methodology whereby machine tools may be structurally generated from simple geometric objects [20, 21, 22,]. Researchers at the University of Michigan further extrapolated this methodology into the fabrication of a library of 
precompiled mechanical modules from which machine tools may be assembled [5, 9, 11]. Supplementary to the organisation of mechanical modules into a library is the methodology of module enumeration developed by Ouyang et al. [23]. Moon and Kota have developed a mathematical framework for the synthesis of a kinematically viable machine tool from a library of mechanical building blocks [10, 24]. Interfacing techniques for mechanically modular machines are discussed extensively by Able et al. [18] and Landers et al. [4].

\subsection{Reconfigurable machine tools}

The Arch Type RMT presented by Katz et al. [12] is the most significant development in RMT technology to date. This machine tool was developed around a part family of V8 and V6 engine blocks, and performed machining operations on various inclined surfaces. Although designed from a library of machine modules, the Arch Type RMT did not exhibit modularity, in the sense that machine modules could not be added to or removed from the platform to enhance or diminish the machine's functionality. MRM technology has been developed on principles established in RMT technology; however the key distinction is the design orientation. Unlike RMTs, MRM technology is not part family orientated. The fully modular nature of the machine, including the modular OAC system, permits the machine to be adapted to the production of multiple part families, while still being customisable to the machining task at hand.

\subsection{Open architecture control}

Open architecture controllers (OAC) are aimed at eliminating the problem of implementation by creating a flexible control system that can be attached to a wide variety of machine tools. Furthermore, proprietary controllers and additional sensory infrastructure are expensive to upgrade, and present hindrances in interfacing these machines with a higher control system [9]. The advent of faster processors for personal computers (PCs) and a general reduction in prices has increased the use of PC-based controllers. PC-based controllers are generally flexible and open, and can easily be integrated into multiple manufacturing configurations [13]. These attributes help to enhance productivity and reduce maintenance costs. In recent years, organisations like Open Systems Architecture for Controls within Automation systems (OSACA) and Open Modular Architectures Controllers (OMAC), and academic institutions like the University of Michigan and the University of British Columbia, have either drawn standards or developed an open architecture controller for machine tools. Most controllers of this nature are implemented using PCs supporting a real-time operating system (RTOS), including the utilisation of communication networks such as PROFIBUS and SERCOS. Peripheral devices such as digital signal processing (DSP) boards and microcontrollers are then used for low-level processing and $1 / 0$ operations. Although several controllers have been successfully implemented, much work is still needed to improve openness and real-time performance.

\subsection{Real-time operating systems}

Machine tools require robust real-time motion control capabilities in which time constraints are critical to maintaining the accuracy and integrity of a product. PC-based real-time operating systems (RTOS) are generally implemented as the real-time system of choice [13]. RTOS have the ability to schedule tasks according to performance critical priorities, quickly recover from errors, provide fast switching between tasks, and - most significantly they are extensible. The presence of characteristics like multi-threadedness, preemptability, thread priority, predictable thread synchronisation mechanisms, priority inheritance, and predefined latencies (predictable) in an operating system make PC-based RTOS suitable for real-time machine control. Thus far RTOS like the QNX and other UNIXbased OS have been implemented and tested in manufacturing situations. In enhancing the extensibility of the machine's controller, the development of a modular real-time open architecture controller $(\mathrm{OAC})$ has been initiated. 


\section{MRM - MECHANICAL ASPECTS}

\subsection{Module types}

MRMs are fully modular in nature. The mechanical modules from which an MRM is created have the ability to be assembled in a 'building block' fashion. This permits the mechanical modules to be assembled in multiple configurations, providing a variation of the machining degrees of freedom (DOF) and machining functions on a single platform. The primary stage in the development of an MRM is the synthesis of a library of precompiled mechanical modules, from which only the necessary modules are selected to provide the required machine configuration. Figure 1 illustrates such a library.

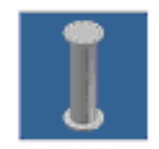

HArw-T1-7SOWn

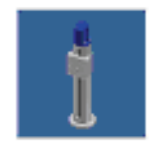

Mode-Columritisa.

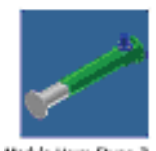

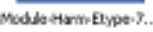

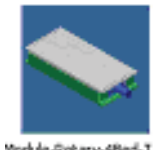

Vodulatactary.4Bed-1.

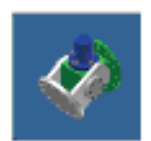

Mode-angeten

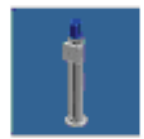

ModbecolumerT200..

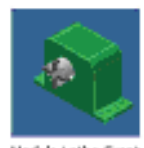

Noduk Lathefiuth

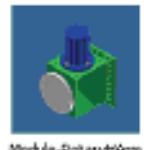

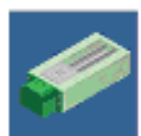

Hooleters
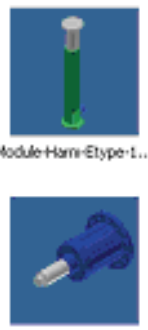

hodic powerpadif?

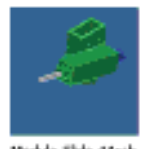

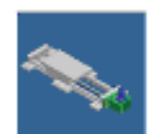

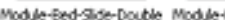
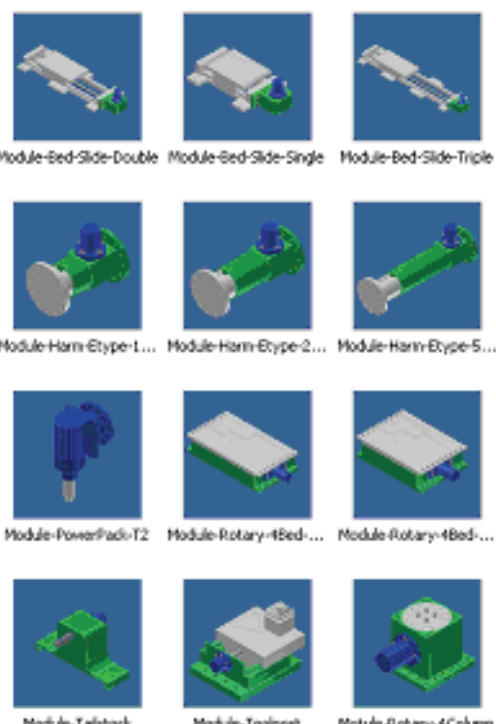

Figure 1: A library of mechanical modules for MRMs [17]

Modules within a library are classified into three categories: Function, Motion, and Accessory. Function modules are interchangeable modules that provide a machining process. Each function enables one of the following machining processes: drilling, milling, tapping, boring, grinding, polishing, engraving, and turning. The functionality of a machine tool is reconfigured through the variation of function modules as the end effectors of a system. Figure 2 illustrates this.
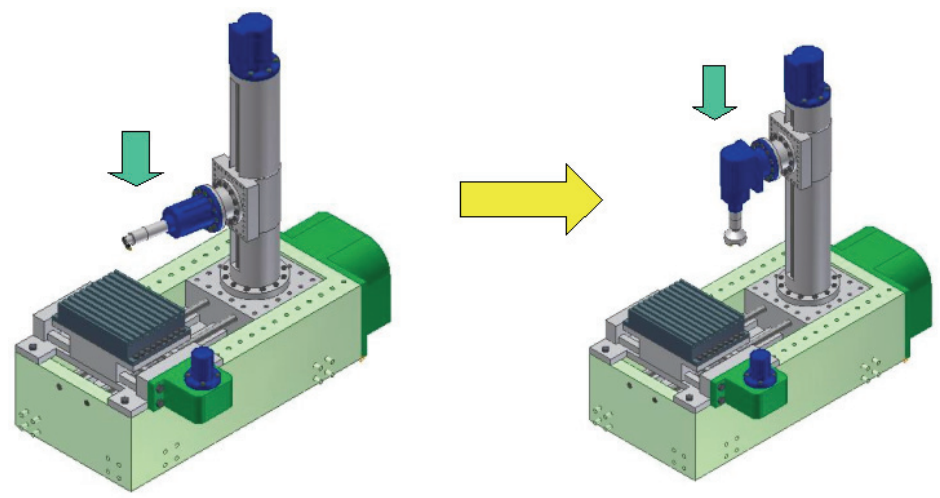

Figure 2: A reconfiguration of machining functionality [17] 
Motion modules are modules that contribute to the degrees of freedom (DOF) possessed by a machine tool. The platform developed possessed a minimum of three DOF (translations along the $\mathrm{X}, \mathrm{Y}$ and $\mathrm{Z}$ axes of a Cartesian coordinate system). Additional motion enhancement modules were then created enabling a variability of $3,4,5$, and 6 DOF on a single platform.
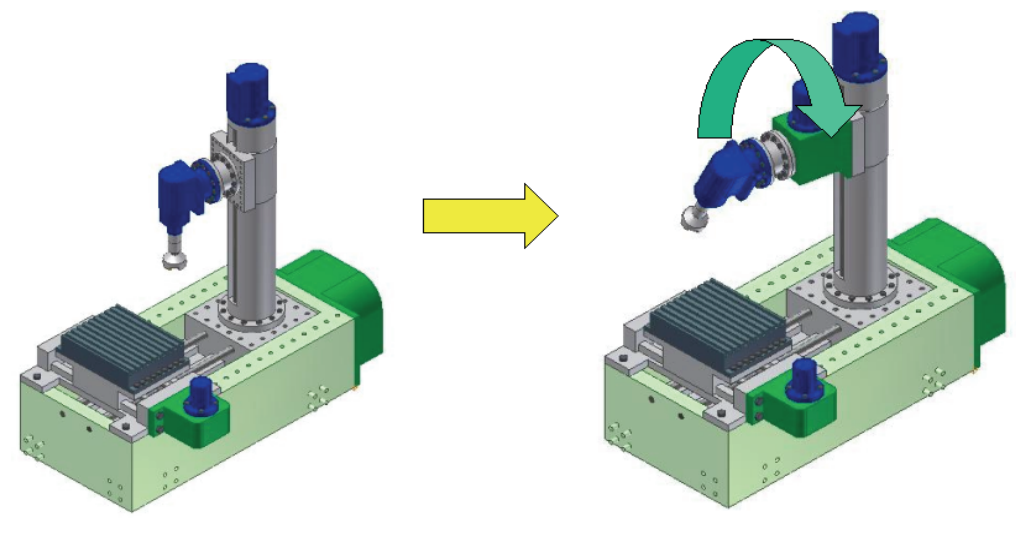

Figure 3: A reconfiguration of machining DOF [17]

Each additional DOF is added through the integration of a motion module. A total of eight different kinematic configurations were achievable on a single platform. Such reconfigurability has thus far not been displayed by commercial machine tools or academic prototypes. Figure 3 illustrates the reconfiguration of machining DOF through the integration of a motion module.

The third class of modules used in the assembly of an MRM is Accessory modules. These are not directly involved in the cutting process; however they are essential to the successful completion of a task. Such modules include work clamps and stabilisers.

\subsection{Module architecture}

All modules within the library possess three types of standardised interfaces that enable the integration of modules in a building block fashion. These are standardised mechanical, power, and control interfaces. Standardised mechanical interfaces facilitate physical interconnectivity between modules. A standardised mechanical interface further allows multiple types of modules to be connected to a single interface, enabling a reconfiguration of machine topology. The MRM developed implements bolted interfaces, the performance of which is discussed in Section 6. The bolt material is specified to be of higher elasticity than the module interfaces, thus limiting first order errors in the form of interface deformation and protecting modules from mechanical damage under excessive loading conditions. Each module contains a DC motor and other mechanical actuation gear that enables the module to provide a required motion. Power to the mechanical actuation gear is supplied via the standardised power interface. This allows the module to be connected to external motor control circuitry performing PWM. Embedded within each motion module was a three-channel 500 PPR encoder, facilitating position control. Function modules contained a dual axis accelerometer for vibration sensory feedback. All sensory information is fed back to external control circuitry via the standardised control interface. Control circuitry is housed externally to each module. The choice not to embed intelligence within a module was based on ease of accessibility to control circuitry for upgrades and repairs. 


\section{CONTROL SYSTEM}

\subsection{PC-based open architecture control}

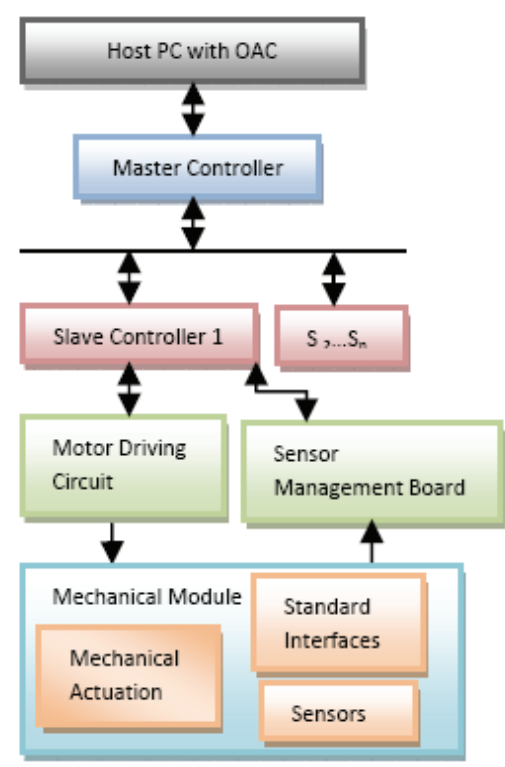

Figure 4: Hardware schematic of system [17]

Illustrated in Figure 4 is the complete electronic hardware architecture of the control system. The system is fully modular and distributed. The modularity of the system facilitates scalability, where the processing potential of the controller may be increased, as outlined in Section 5.1. The distributed nature of the system improves maintainability, promoting cost-effective repairs and upgrades. The head of the control system is the host PC supporting an OAC system. The host PC is responsible for all calculations involving kinematics and calculations related to the trajectory of the tool. The PC-based control architecture of the system is based on the OSACA reference model illustrated in Figure 5.2. Real-time (RT) Linux has been selected as the RTOS. In addition to being an open source platform, RT-Linux has short scheduling and interrupt latencies [13]. RT-Linux has been shown to have a worst case scheduling latency of $25 \mu \mathrm{sec}$ on a $300 \mathrm{MHz}$ and $128 \mathrm{MB}$ Pentium II machine. The host PC of the MRM platform has a processor speed of $2 \mathrm{GHz}$ and is equipped with $1 \mathrm{~GB}$ of RAM.

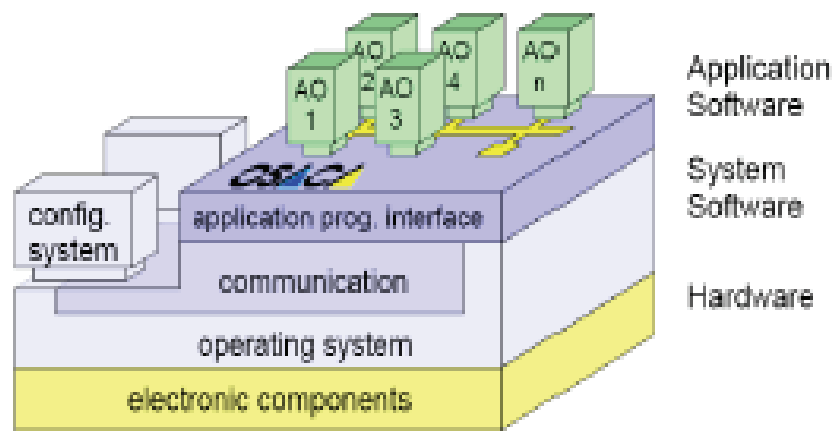

Figure 5: The OSACA reference model [14] 
In the development of prototype software, data abstraction and object-oriented style were the focus in implementation. This style is characterised by encapsulation of data and its primitive operations into abstract data called objects [15]. The ability of an object to conceal its representation from clients makes it possible to change the implementation without affecting the client. The bundling of a set of accessing routines with the data they manipulate enables programmers to decompose problems into a collection of interacting agents. $\mathrm{C}++^{+}$an object-oriented programming language, was used for the implementation, thus enhancing software modularity and reconfigurability.

\subsection{Master control module}

The host PC interfaces with a master control module via USB, as illustrated in Figure 4. The main function of the master control module is the routing of instructions between the host PC and the appropriate slave control module (axis drive module). The Linux operating system provided a virtual COM port driver, which is built into kernel versions 6.2.9 and later [19]. This enabled software communication structures to perform I/O operations with the simplicity of RS232 communication, while maintaining the advantages of speed, scalability, and 'hot plugging' offered by the USB communication protocol. The master control module is an ATmega32-based microcontroller board that incorporates an FT232 chip, thus enabling the conversion of USB signals into a UART format that the ATmega32 chip is able to use. The master control module receives instructions for routing from the host PC to slave modules in the form of the packet protocol illustrated in Table 1.

\begin{tabular}{|c|c|c|}
\hline Sequence & Function & Data Size \\
\hline 1 & Routing address & 1 Byte \\
\hline 2 & Pulse count (Distance) & 4 Bytes \\
\hline 3 & Pulse rate (Speed) & 4 Bytes \\
\hline 4 & Miscellaneous & $\begin{array}{l}1 \text { Byte } \\
\text { Bit 7: Direction of motion } \\
\text { Bits 0-6: Reserved for module-specific functions }\end{array}$ \\
\hline
\end{tabular}

Table 1: Data packet from host PC to master control module

The first byte of the packet is the module address to which the following data bytes must be routed. Although one byte is dedicated to addressing, the $\mathrm{I} 2 \mathrm{C}$ protocol, implemented in lower layers of the system, allows for a maximum address length of 7 bits. An address length of 7 bits limited the modularity of the system to 128 addressable modules. The next pair of four bytes is the pulse count and pulse rate that servomotors of a module must achieve. Pulse rate and pulse count are stored in the ' $C$ ' float data type, enabling a range of values in decimals from $\pm\left(3.4 \times 10^{-38}\right.$ to $\left.3.4 \times 10^{38}\right)$, which is significantly larger than the range of values an MRM will be required to execute in any physically feasible user program. The first bit of the last byte in the packet is used to specify the direction of module movement, while the remaining seven bits are reserved for auxiliary instructions specific to each module.

\subsection{Slave control modules and sensor management}

Slave control modules are networked together on an $12 \mathrm{C}$ network. Individual slave modules map to mechanical modules on a 1:1 basis. For each new mechanical module integrated into an MRM platform, a corresponding slave module is added to the network. Slave modules provide a PWM control signal to $\mathrm{H}$-Bridge motor driving circuits, as well as receive feedback from a sensor management board. Feedback from the sensor management board is via UART. Table 2 illustrates the data packet that a slave control module would transmit to the host PC, after a corresponding mechanical module has executed the instruction set described in Table 1. The first byte of the packet is the address of the module that is reporting its status to the host PC. The second byte is a status code used to signal the following information: 
- Bit 0: Successful/ unsuccessful completion of instruction set

- $\quad$ Bits 1 - 5: Error detection from sensor data

- $\quad$ Bit 6: Technical problem within the module

- $\quad$ Bit 7: Module due for routine service

\begin{tabular}{|c|c|c|}
\hline Sequence & Function & Data Size \\
\hline 1 & Module address & 1 Byte \\
\hline 2 & Status/Error report & 1 Byte \\
\hline
\end{tabular}

Table 2: Data packet from slave module to host PC via master

\section{RECONFIGURATION}

\subsection{Machine reconfiguration}

The complete range of modules that a machine builder may develop represents a generic machining solution for RMS. From this range of modules, an exact solution may be derived through the acquisition of only those modules required for the synthesis of the necessary machine tool. From an economic perspective, the ability to customise machinery from the time of purchase implies that the cost of flexibility need not be part of the initial investment [18]. The machine's functional flexibility may be reconfigured at a later stage through the integration of other library modules. Machine reconfiguration takes place at three levels: reconfiguration of the mechanical platform, the control hardware, and the control software. The mechanical reconfiguration of the platform is currently a manual process. Each time a unit of mechanical hardware is integrated into the platform, a corresponding slave module is added to the $12 \mathrm{C}$ network; this completes the mechanical and electronic hardware reconfiguration. Individual slave modules map to mechanical modules on a 1:1 basis, where each microprocessor-based slave module contains the necessary software algorithms for the management and control of its matching mechanical hardware module. The last stage of reconfiguration involves the reconfiguration of the control software at the host PC.

Reconfiguration at this level entails the alteration of the control software configuration for the management of the MRM's new kinematic capabilities and control hardware. Reconfiguration of the controller is done through a machine calibration routine on the host PC. In this routine a user is required to input parameters on the machine's kinematic configuration, the physical characteristics of individual modules, the addresses of all new slave microcontroller modules on the $12 \mathrm{C}$ network, and lastly, information on the mapping between mechanical modules and slave modules.

\subsection{Reconfiguration of system production capacity - an example}

In manufacturing systems producing multiple product types, managers are frequently faced with the challenge of redistributing system resources between operations as the demand characteristics of the individual products vary over a period of time. Changes in a demand characteristic are most profound as a new product is launched into a market while a similar older product is being phased out. 

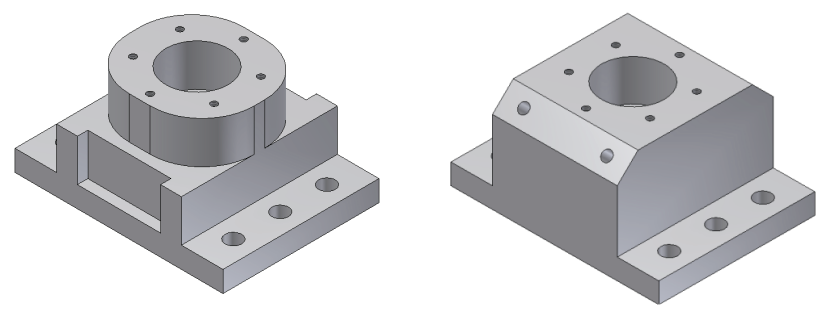

Figure 6: Part A (left), Part B (right)

Figure 6 illustrates two parts belonging to two different products. Part A corresponds to Product $A$, which is being phased out of production. Part $B$ corresponds to Product $B$, which is replacing the old product. Figure 7 illustrates the characteristic curve for the market demand of each product in conjunction with required system capacity for Parts $A$ and $B$. Part $A$ requires a 3 -axis milling machine for its fabrication, while Part $B$ requires a 4 -axis milling machine to cater for the machining of additional inclined surfaces and holes. In this case, a manufacturer would reallocate a portion of the system resources previously used in the production of $A$ to the production of $B$, based on the demand characteristic of Figure 7 .

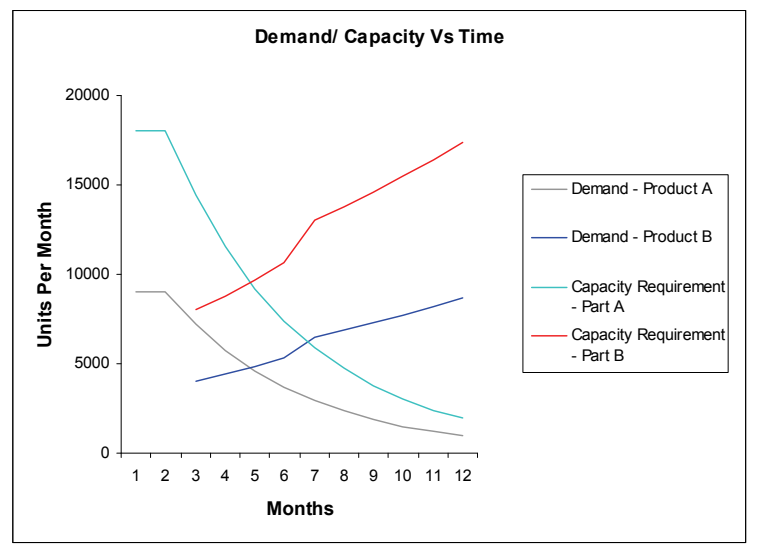

Figure 7: Demand characteristic for products A and B

The required machine reconfiguration is illustrated in Figure 3. If specified that the 3 -axis machine were capable of a production rate of 1,800 units/month, while the 4 -axis configuration were capable of a rate of 1,700 units/month, the distribution of system resources would be as per Figure 8 across the 12-month period. During this period the production requirement of Part A dropped from 18,000 units/ month to 1,933 units/month. At the beginning of the third month Part $B$ was introduced into the system at a requirement of 8,000 units/month rising to a final rate of 17,400 units/month. During the initialisation of Part $B$, three machines were purchased, while two were available for reconfiguration. At the end of the period a total of eight machines that were previously used in the production of Part A were reconfigured for the production of Part B. Due to the modular nature of MRMs, scalability of production capacity and functionality is easily and cost effectively achieved, as illustrated. At all times the machines of the system possess only the functionality required by the system. The property of 'customisable flexibility' that MRMs display allows a minimal initial investment in the system while permitting cost-effective scalability of system functionality and capacity. 


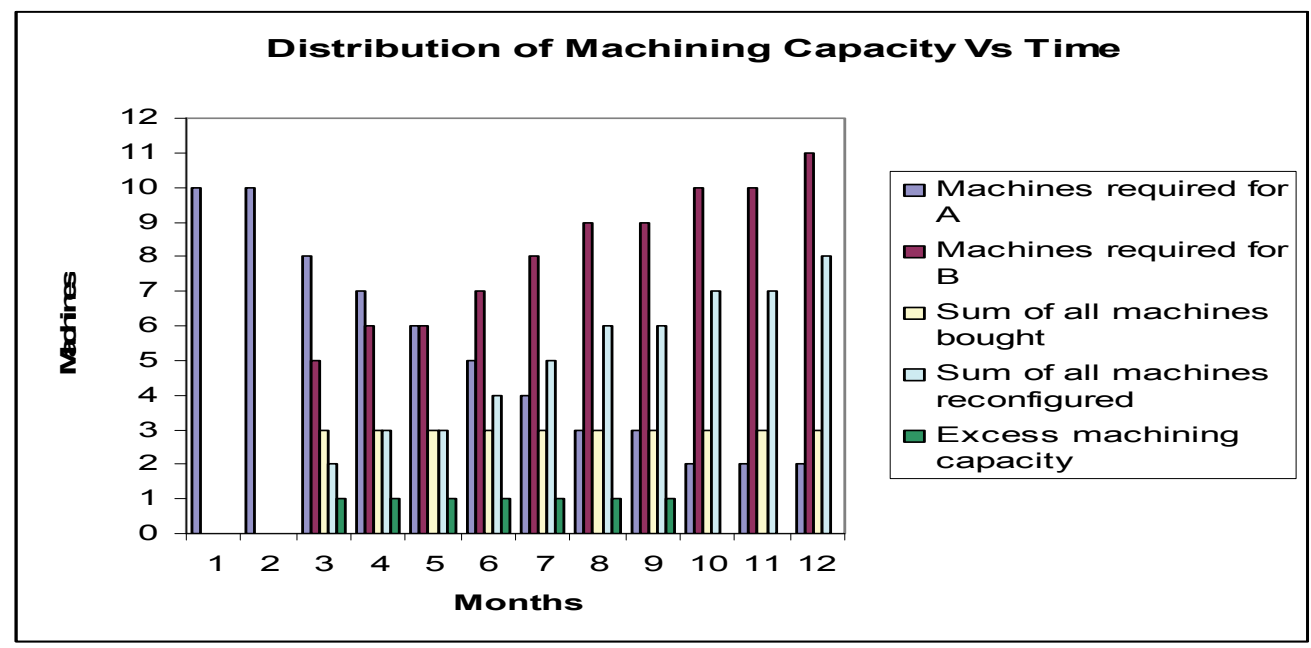

Figure 8: Distribution of machining resources

The scaling of production capacities for individual products is a restricted operation in manufacturing systems possessing CNC machines. If a change of product results in production requirements that fall out of the machining functionality of existing CNC machines, a full quota of new machines 'must be purchased. Conversely, a manufacturer may invest in CNC machines that possess maximal functionality during the initial system installation. This is undesirable, however, as the initial investment in the system would be high, and much of the functionality possessed might remain unused for long periods. The ability to purchase or lease smaller modularised units of hardware that improve system functionality and capacity when required greatly improves the economy of RMS above other paradigms. When production requirements are less demanding of system resources, modules may be sold or returned from lease.

\section{THE INTEGRITY OF MODULAR STRUCTRES IN MACHINING APPLICATIONS}

\subsection{First order errors}

An MRM's capacity to position a cutting tool accurately relative to a work piece is an essential criterion in evaluating the feasibility of implementing this technology. Tool positioning errors are comprised of first and second order components [18]. First order errors result in dimensional inaccuracies in machined components. These errors are attributed to three factors:

i. Geometric positioning errors between adjacent interfaces

ii. Static errors: deflections due to forces on modules, excluding impulse forces

iii. Thermal expansion/contraction errors

\subsubsection{Geometric positioning / assembly errors}

Geometric positioning errors are introduced into an MRM structure during module assembly / reconfiguration. Module interface connectors create stress concentrations around fastening points, which may lead to interface deformation. If interface connectors are specified to be of a more elastic material than a module (module interface), it is reasonable to assume that no interface deformation occurs during machine assembly. Although the geometric errors may be minute for properly designed interfaces and connectors with reasonable design tolerances, the accumulation of these minute errors across a significant number of connected modules may be noticeable. The documentation of these errors is for the purpose of evaluating the suitability of MRMs for high precision 
machining applications. Figure 9 illustrates the three parameters that quantify this category of error.

A)

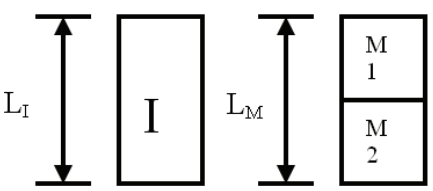

B)

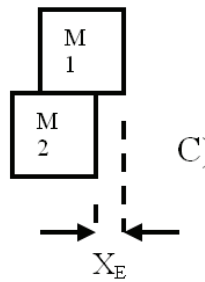

C)
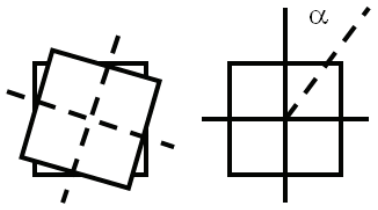

Figure 9: A) Concatenation error, B) Edge offset error, C) Skewness error

The first error, called the concatenation error, is defined as:

$E_{C}=L_{1}-L_{M}$

where $L_{1}$ is the length of an integrated structure, and $L_{M}$ is the length of a similar structure having been created out of two modules instead of one integral piece. The second geometric positioning error parameter is an edge offset defined by the symbol ' $E_{0}{ }_{1}$ ' or ' $E_{0}$ 2 ' if more than one edge is offset. The third error, 'skewness', defined by the angle ' $\alpha$ ', is a measure of the rotation of module two about the geometric centre of module interfaces one and two.

\subsubsection{Static errors}

Static errors result from deflections caused by gravity and operational forces being transmitted throughout the modular structure. Based on the specification that module interface connectors be created from a softer material than the modules themselves, it is reasonable to presume that the deflections incurred would be most profound in the interface connectors. Figure 10 illustrates the loading situations that adjacent modules may be subjected to.

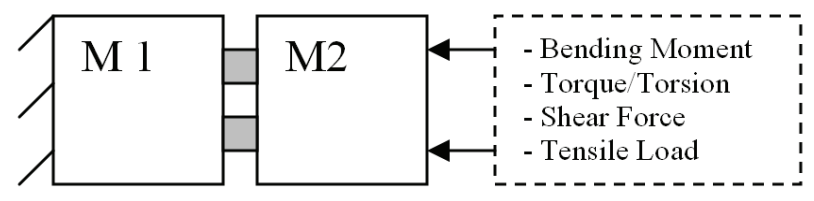

Figure 10: Loading scenarios on adjacent modules

The load combination and the orientation of the interface on an adjoining module may cause an additional static concatenation error, a skewness error, or an edge offset error. By limiting the deflections incurred on the linear elastic deformation boundary of each material, the space of the static error is defined by:

$E_{\text {Static }}=f\left(E_{\text {C-STATIC }}, E_{\text {O 1-STATIC }}, E_{\text {O } 2 \text {-STATIC }}, \alpha_{\text {STATIC }}\right)$

\subsubsection{Accumulated first order error}

In considering first order errors, thermal errors have been neglected. Combining assembly and static errors, yields the following:

$\mathrm{E}_{\text {C-TOTAL }}=\mathrm{E}_{\mathrm{C}-\text { STATIC }}+\mathrm{E}_{\text {C-ASSEMBLY }}$

$E_{O 1-T O T A L}=E_{O 1-S T A T I C}+E_{O 1-A S S E M B L Y}$

$E_{O 2-T O T A L}=E_{E \text { 2-STATIC }}+E_{E \text { 2-ASSEMBLY }}$

$\alpha_{\text {TOTAL }}=\alpha_{\text {STATIC }}+\alpha_{\text {ASSEMBLY }}$ 
If a Cartesian coordinate system were placed on the interface of module one, with the Zaxis perpendicular to the interface, equations (3)-(6) might be translated into a static error transformation matrix as follows:

$$
E_{n-1 \leftarrow n}=\left[\begin{array}{cccc}
\cos \alpha_{T} & -\sin \alpha_{T} & 0 & E_{O X-T} \\
\sin \alpha_{T} & \cos \alpha_{T} & 0 & E_{O Y-T} \\
0 & 0 & 0 & E_{C-T} \\
0 & 0 & 0 & 1
\end{array}\right]
$$

The total system transformation matrix, excluding errors, is calculated by:

$$
T_{\text {tool }}^{\text {worktable }}=M_{1} M_{2} \ldots M_{n}
$$

where $M_{n}$ is a transformation matrix describing the kinematic relationship between the two interfaces of module $\mathrm{n}$. The total system transformation matrix, including errors, is calculated by:

$$
T E_{\text {tool }}^{\text {workable }}=M_{1} E_{1 \leftarrow 2} M_{2} E_{2 \leftarrow 3} \ldots M_{3} E_{n-1 \leftarrow n}
$$

The total first order error in tool tip position relative to a fixed axis on the worktable is calculated by:

$$
P E_{\text {tool }}^{\text {worktable }}=T E_{\text {tool }}^{\text {worktable }}\left[\begin{array}{c}
x_{\text {tool }} \\
y_{\text {tool }} \\
z_{\text {tool }}
\end{array}\right]-T_{\text {tool }}^{\text {worktable }}\left[\begin{array}{c}
x_{\text {tool }} \\
y_{\text {tool }} \\
z_{\text {tool }}
\end{array}\right]
$$

\subsubsection{Investigation: First order errors}

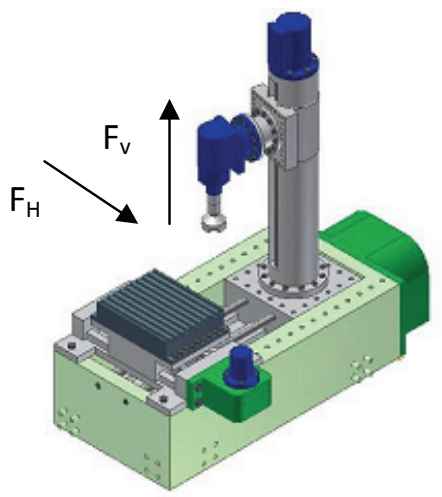

Figure 11: Forces applied to a 3-axis milling configuration

Vertical and horizontal forces are applied to the cutting tool of a 3-axis vertical milling machine, to investigate the magnitude of first order errors between the cutting tool and an absolute coordinate system fixed to the machine base. The loading scenario is illustrated in Figure 11. Three interfaces exist between the machine tool and base:

1. Milling function module $\rightarrow$ Machine arm

2. Machine arm $\rightarrow$ Machine column

3. Machine column $\rightarrow$ Machine base 
The investigation was performed on a scaled-down modular machine constructed at the $M R^{2} G$ laboratory (University of KwaZulu-Natal).

Module interfaces are connected by eight M6x1 bolts equally spaced on a PCD of $160 \mathrm{~mm}$. The magnitudes of the applied forces are $F_{V}=F_{H}=6500 \mathrm{~N}$. The selection of these magnitudes is such that the bolts connecting the machine column to the base are at the brink of plastic deformation, i.e. maximum elastic deformation. Table 3 displays the results of the static concatenation, edge offset, and skewness errors existing at each interface for the applied loads.

\begin{tabular}{|c|c|c|c|c|}
\hline Interface & $\begin{array}{c}\mathrm{E}_{\mathrm{C}} \\
(\mathrm{mm})\end{array}$ & $\begin{array}{c}\mathrm{E}_{\mathrm{OX}} \\
(\mathrm{mm})\end{array}$ & $\begin{array}{c}\mathrm{E}_{\mathrm{OY}} \\
(\mathrm{mm})\end{array}$ & $\begin{array}{c}\alpha \\
(\text { Degrees })\end{array}$ \\
\hline 1 & 0 & $2.13 \mathrm{E}-11$ & $2.13 \mathrm{E}-11$ & $1.74 \mathrm{E}-11$ \\
\hline 2 & 0 & $2.13 \mathrm{E}-11$ & $1.28 \mathrm{E}-07$ & $1.74 \mathrm{E}-11$ \\
\hline 3 & $1.44 \mathrm{E}-07$ & $-9.60 \mathrm{E}-08$ & $2.24 \mathrm{E}-07$ & $2.33 \mathrm{E}-11$ \\
\hline
\end{tabular}

Table 3: Maximum static errors corresponding to each interface

A maximum clearance fit of $0.029 \mathrm{~mm}$ has been specified between the bolts and connection points on adjacent interfaces. Table 4 displays the maximum possible assembly errors as per the specified clearance fit. A comparison with assembly errors reveals that the static errors incurred by mechanical loading were smaller by a minimum difference of $10^{-5} \mathrm{~mm}$.

\begin{tabular}{|c|c|c|c|c|}
\hline Interface & $\begin{array}{c}\mathrm{E}_{\mathrm{C}} \\
(\mathbf{m m})\end{array}$ & $\begin{array}{c}\mathrm{E}_{\mathrm{OX}} \\
(\mathbf{m m})\end{array}$ & $\begin{array}{c}\mathrm{E}_{\mathrm{OY}} \\
(\mathbf{m m})\end{array}$ & $\begin{array}{c}\alpha \\
(\text { Degrees })\end{array}$ \\
\hline 1 & $1.00 \mathrm{E}-04$ & $1.45 \mathrm{E}-02$ & $1.45 \mathrm{E}-02$ & $1.47 \mathrm{E}-02$ \\
\hline 2 & $1.00 \mathrm{E}-04$ & $1.45 \mathrm{E}-02$ & $1.45 \mathrm{E}-02$ & $1.47 \mathrm{E}-02$ \\
\hline 3 & $1.00 \mathrm{E}-04$ & $1.45 \mathrm{E}-02$ & $1.45 \mathrm{E}-02$ & $1.47 \mathrm{E}-02$ \\
\hline
\end{tabular}

Table 4: Maximum assembly error at each interface

The results demonstrate that an interface connection would fail by plastic deformation before contributing significantly to first order errors in the machine tool. The maximum error matrix for all three interfaces is given by:

$E=\left[\begin{array}{cccc}\cos \left(1.47 \times 10^{-2}\right) & -\sin \left(1.47 \times 10^{-2}\right) & 0 & 1.45 \times 10^{-2} \\ \sin \left(1.47 \times 10^{-2}\right) & \cos \left(1.47 \times 10^{-2}\right) & 0 & 1.45 \times 10^{-2} \\ 0 & 0 & 1 & 1 \times 10^{-4} \\ 0 & 0 & 0 & 1\end{array}\right]$

The transformation matrices describing the kinematic relationship between the front and back interfaces of each module are listed below.

$M M=\left[\begin{array}{cccc}1 & 0 & 0 & 0 \\ 0 & 1 & 0 & -300 \\ 0 & 0 & 1 & 200 \\ 0 & 0 & 0 & 1\end{array}\right](12), M A=\left[\begin{array}{cccc}1 & 0 & 0 & 0 \\ 0 & 1 & 0 & 0 \\ 0 & 0 & 1 & 400 \\ 0 & 0 & 0 & 1\end{array}\right]$ (13), $M C=\left[\begin{array}{cccc}0 & -1 & 0 & 0 \\ 1 & 0 & 0 & -200 \\ 0 & 0 & 1 & 1000 \\ 0 & 0 & 0 & 1\end{array}\right]$

The relationship between machine tool tip and the machine base is calculated by equation (15). 


$$
T_{\text {tool }}^{\text {base }}=M C \times M A \times M M
$$

The relationship between machine tool tip and base, including first order errors, is calculated by:

$$
T E_{\text {tool }}^{\text {base }}=M C \times E \times M A \times E \times M M \times E
$$

By substitution into equation (10), the total first order error in tool tip position relative to a fixed axis on the machine base is:

$$
P E_{\text {tool }}^{\text {base }}=T E_{\text {tool }}^{\text {base }}\left[\begin{array}{l}
0 \\
0 \\
0
\end{array}\right]-T_{\text {tool }}^{\text {base }}\left[\begin{array}{l}
0 \\
0 \\
0
\end{array}\right]=\left[\begin{array}{l}
0.1170 \\
0.0435 \\
0.0003
\end{array}\right]
$$

The errors of $0.1170 \mathrm{~mm}$ and $0.0435 \mathrm{~mm}$ in the $X$ and $Y$ directions are sufficiently significant to affect machining operations. The magnitude of these first order errors is primarily due to errors in module assembly.

\subsection{Second order errors}

Second order errors are mainly a result of tool chatter and other vibrations within a machine. These errors are classified as dynamic - $\mathrm{E}(\mathrm{t})$ - and generally affect the surface integrity of a machined component, machine tool wear, and breakage. The magnitude of a second order error depends on module stiffness, machine mass distribution, and interface damping capacity. These errors are specific to the physical attributes of individual modules and module configurations, and cannot be modelled in a universally applicable way [18].

\section{DISCUSSION}

\subsection{Reconfigurability}

The MRM platform displayed a variability of eight processing functions on a single platform. In addition to the cutting processes, the platform further displayed eight different kinematic configurations. In total 64 different functional states were achievable on a single platform. In Section 5 it was demonstrated how the modularity of MRMs aid the scalability of system capacity and functionality between multiple operations. Traditional CNC-based systems are restricted in the redistribution of machining resources based on functional applicability of the machine tool to various operations.

\subsection{MRM assembly errors}

The magnitude of the first order errors calculated in Section 6 was expected, due to the necessary clearance fit between module interface connectors and connection points. Commercial laser machine calibration services may be invoked to provide an accurate measurement of the geometric offsets in a machine tool, typically providing an accuracy of $0.001 \mathrm{~mm}$ on linear measurements. Assembly alignment errors are not envisioned as an obstacle in the feasible implementation of MRMs, provided that machine reconfiguration is followed by the implementation of appropriate error compensation techniques.

\subsection{Accuracy and repeatability}

Each motion module in the MRM module set contained a 500 pulse per revolution quadrature encoder. The pulse count on the encoders enabled a control resolution of 0.036 
degrees on rotational axes and $0.0015 \mathrm{~mm}$ on linear axes. The quadrature encoders were directly coupled to the output shafts of modules, thereby reducing mechanical errors in position feedback loops. The constructed MRM platform possessed a typical accuracy of $0.032 \mathrm{~mm}$ and repeatability of $0.054 \mathrm{~mm}$ on linear axes. A typical CNC machine has a repeatability figure of $0.008 \mathrm{~mm}[16]$. The poor accuracy and repeatability figures obtained were attributed primarily to the use of substandard lead screw and gearbox systems in the MRM prototype; however, the principle of MRMs has been demonstrated.

\subsection{Spindle power and cutter sizes}

The self-contained nature of individual modules required that the motors powering the cutting tools be housed within individual function modules, thereby limiting motor sizes and cutting power. A reduction in motor cutting speeds and torques invariably imposed limitations on the sizes of the cutting tools installed on the platform, resulting in the MRM platform displaying smaller machining capacities in comparison with similar-sized CNC machines.

\section{CONCLUSION}

Frequent changes in product portfolios and fluctuating demand characteristics place strain on the resources of a manufacturing system. The RMS paradigm has been developed to encapsulate methodologies that improve system responsiveness to changes in manufacturing requirements that necessitate intensive adjustment of system functionality and production capacity. Modular reconfigurable machine tools have been presented as a machining solution within the scope of reconfigurable manufacturing that will provide a cost-effective solution when adapting machining resources to production changes. The unique property of 'customisable flexibility' exhibited by MRMs, and the level of reconfigurability achievable, additionally enhance the feasibility of implementation in RMS.

Further research in the field of MRM technology will include an investigation into the feasibility of implementing active vibration damping in the construction of lightweight modular machining structures. The advent of lighter, high-strength, well-damped machining structures would greatly improve the ease of mechanical reconfiguration in MRM platforms, enhancing the attractiveness of a modular machining solution for RMS.

\section{ACKNOWLEDGEMENTS}

We would like to thank the Advanced Manufacturing Technology Strategy (AMTS), together with the Department of Science and Technology, for the provision of project funding. We also thank the University of KawZulu-Natal and the Council for Industrial and Scientific Research (CSIR) for the provision of infrastructure and resources during this research.

\section{REFERENCES}

[1] Sung-Yong Son, Tava, Lennon Olsen and Yip-Hoi, Derek. 2001. An approach to scalability and line balancing for reconfigurable manufacturing systems, Integrated Manufacturing Systems, Volume 12, Issue 7.

[2] Mehrabi, M.G., Ulsoy, A.G., Koren, Y. and Heytler, P. 2002. Trends and perspectives in flexible and reconfigurable manufacturing systems. Journal of Intelligent Manufacturing, Issue 13, pp. 135-46.

[3] Koren, Yoram. 2004 Reconfigurable manufacturing systems, Proceedings: International Conference On Competitive Manufacturing, COMA '04, pp. 69-79, Stellenbosch, South Africa (February 2004). 
[4] Li. H., Landers. R. and Kota S. 2000. A review of feasible joining methods for reconfigurable machine tool components, Proceedings of the Japan-USA symposium on flexible automation, Pp. 381-388. Ann Arbor, MI, USA.

[5] Koren, Y., Heisel, U., Jovane, F., Moriwaki, T., Pritschow, G., Ulsoy, G. and van Brussel, H. 1999. Reconfigurable manufacturing systems, Annals of the CIRP, Volume 48/2, pp. 527-540,

[6] Xu, X.W. and Newman, S.T. 2006. Making CNC machine tools more open, interoperable and intelligent: Review of the technologies, Computers in Industry, Volume 57 Issue 2 (February 2006), pp. 141-152.

[7] Setchi, R.M. and Lagos, N. 2004. Reconfigurability and reconfigurable manufacturing systems: State-of-the-art review, Industrial Informatics, $2^{\text {nd }}$ IEEE International Conference, 24-26 June 2004, pp. 529-535.

[8] Landers, R.G., Min, B.K. and Koren, Y. 2001. Reconfigurable machine tools, CIRP Annals - Manufacturing Technology, Volume 50 Issue 1, pp.269-274.

[9] Mehrabi, M.G., Ulsoy, A.G. and Koren, Y. 2000. Reconfigurable manufacturing systems and their enabling technologies, International Journal of Manufacturing Technology and Management, Vol. 1 No. 1, pp. 113-130.

[10] Moon, Yong-Mo and Kota Sridhar. 2002. Design of reconfigurable machine tools, Journal of Manufacturing Science and Engineering Volume 124 Issue 2 (May 2002), pp. 480-483.

[11] Tilbury, D.M. and Kota S. 1999. Integrated machine and control design for reconfigurable machine tools, Proceedings: Advanced Intelligent Mechatronics, 1999 IEEE/ASME International Conference, pp. 629-634.

[12] Katz, R. and Moon, Y.-M. 2000. Virtual arch type reconfigurable machine tool design. The University of Michigan, Ann Arbor, USA.

[13] Kommareddy, S., Kazuo, Y. and Yoshihito. K. 2000. PC-based open architecture servo controller for CNC machining, Proceedings of the Second Real-Time Linux Workshop, Orlando, USA (20-27 November 2000).

[14] Sperling, Wolfgang and Lutz, Peter. 1997 Designing applications for an OSACA control, Proceedings of the International Mechanical Engineering Congress and Exposition (The ASME Winter Annual Meeting). Dallas/USA, November 16-21, 1997

[15] Atta-Konadu, R. 2006. Design and implementation of a modular controller for robotic machines. Doctoral thesis, University of Saskatchenwan.

[16] Crandell, C.M. 2003. CNC machining and programming: An introduction. $2^{\text {nd }}$ edition. Industrial Press Inc, New York.

[17] Padayachee, J., Masekamela, I., Bright, G., Kumile, C. and Tlale, N.S. 2008. Modular reconfigurable machines incorporating open architecture control. $15^{\text {th }}$ International Conference on Mechatronics and Machine Vision in Practice (M2VIP'08), Auckland, New Zealand (2-4 December 2008).

[18] Abele, Eberhard; Wörn, Arno; Fleischer, Jürgen; Wieser, Jan; Martin, Patrick and Klöpper, Robert. 2007. Mechanical module interfaces for reconfigurable machine tools, Prod. Eng. Res. Devel. 1:421-428.

[19] Virtual COM port drivers: http://www.ftdichip.com/Drivers/VCP.htm. 02 April 2009 
[20] Shinno, H. and Ito, Y. 1981. Structural description of machine tools 1: Description method and application, Bulletin of the JSME, 24(187):251-258 (January 1981).

[21] Shinno, H. and Ito, Y. 1981. Structural description of machine tools 2: Evaluation of structural similarity, Bulletin of the JSME, 24(187):259-265 (January 1981).

[22] Shinno, H. and Ito, Y. 1984. A proposed generating method for the structural configuration of machine tools. ASME Winter Annual Meeting, 1984. ASME paper 84WA/Prod-22.

[23] Ouyang, M.A., Yi, C., Li, C. and Zhou, J. 1995. Intelligent layout for modular design of machine tools. SPIE, 2620:547-552.

[24] Moon, Yong-Mo and Kota, Sridhar. 2002. Generalized kinematic modeling of reconfigurable machine tools, Journal of Mechanical Design, Vol. 124 (March 2002), pp. 47-51.

[25] Ayman M.A., Youssef, Hoda and ElMaraghy, A. 2006. Assessment of manufacturing systems reconfiguration smoothness, International Journal of Advanced Manufacturing Technology 30: 174-193. 